\title{
Sluggish decline in a post-transplant model for end-stage liver disease score is a predictor of mortality in living donor liver transplantation
}

\author{
Won Jung Hwang, Joon Pyo Jeon, Seung Hee Kang, Hyun Sik Chung, Ji Yong Kim, and Chul Soo Park
}

Department of Anesthesiology and Pain Medicine, Seoul St. Mary's Hospital, The Catholic University of Korea, Seoul, Korea

Background: The pre-transplant model for end-stage liver disease (pre-MELD) score is controversial regarding its ability to predict patient mortality after liver transplantation (LT). Prominent changes in physical conditions through the surgery may require a post-transplant indicator for better mortality prediction. We aimed to investigate whether the post-transplant MELD (post-MELD) score can be a predictor of 1-year mortality.

Methods: Perioperative variables of 269 patients with living donor LT were retrospectively investigated on their association with 1-year mortality. Post-MELD scores until the 30th day and their respective declines from the 1st day post-MELD score were included along with pre-MELD, acute physiology and chronic health evaluation (APACHE) II, and sequential organ failure assessment (SOFA) scores on the 1st post-transplant day. The predictive model of mortality was established by multivariate Cox's proportional hazards regression.

Results: The 1-year mortality rate was $17 \%(n=44)$, and the leading cause of death was graft failure. Among prognostic indicators, only post-MELD scores after the 5th day and declines in post-MELD scores until the 5th and 30th day were associated with mortality in univariate analyses $(\mathrm{P}<0.05)$. After multivariate analyses, declines in post-MELD scores until the 5 th day of less than 5 points (hazard ratio $2.35, \mathrm{P}=0.007$ ) and prolonged mechanical ventilation $\geq 24$ hours were the earliest independent predictors of 1-year mortality.

Conclusions: A sluggish decline in post-MELD scores during the early post-transplant period may be a meaningful prognostic indicator of 1-year mortality after LT. (Korean J Anesthesiol 2010; 59: 160-166)

Key Words: Liver transplantation, Living donor, Mortality, Prediction.

Received: April 14, 2010. Revised: 1st, April 20, 2010; 2nd, May 14, 2010. Accepted: June 4, 2010.

Corresponding author: Chul Soo Park, M.D., Department of Anesthesiology and Pain Medicine, Seoul St. Mary's Hospital, The Catholic University of Korea, 505, Banpo-4 dong, Seocho-gu, Seoul 137-701, Korea. Tel: 82-2-2258-2235, Fax: 82-2-537-1951, E-mail: p6c8s17@catholic.ac.kr (c) This is an open-access article distributed under the terms of the Creative Commons Attribution Non-Commercial License (http:// creativecommons.org/licenses/by-nc/3.0/), which permits unrestricted non-commercial use, distribution, and reproduction in any medium, provided the original work is properly cited. 


\section{Introduction}

Liver transplantation (LT) is usually has higher mortality rates than other types of surgery due to acute hepatic failure, graft size-related problems, ischemic time, original disease recurrence, cardiovascular complications, and infection [1-3].

Early determination of mortality factors are important for proper patient management using pre-transplant or intraoperative factors [4,5]. One prognostic marker is the model for end-stage liver disease (MELD) score, which was originally developed for predicting early mortality in patients waiting for LT [6]. Patients with higher MELD scores usually have more preoperative comorbidities and laboratory abnormalities, so pre-transplant MELD (pre-MELD) score can help predict pre-transplant fatal outcomes [7]. Despite controversy [8], the pre-MELD score is not generally a useful indicator of posttransplant mortality or in pre-transplant situations [9].

Patients after LT have much different physical conditions than pre-transplant periods. Graft-related problems cause more than $50 \%$ percent of late deaths [2]. MELD score is based primarily on liver-related laboratory findings such as bilirubin and international normalized ratio of prothrombin time (INR). Therefore, patients with changed liver conditions should receive a new MELD score. MELD score is partly driven by creatinine and can reflect post-transplant deterioration in renal function as well. Although pre-transplant renal dysfunction improves after transplantation [10], LT also leads to chronic renal disease, which can contribute to graft and patient survival [11].

Clearly, pre-transplant cross-sectional assessment of disease severity is important in predicting patient outcomes. However, re-evaluation or follow-up observation in the early post-transplant period may be more valuable for accurate prediction of long-term outcomes after surgery. Studies on post-transplant MELD (post-MELD) scores are rare, although it may be a predictor for short-term mortality $[12,13]$. An initially high MELD score in the immediate post-transplant period may decrease, increase, or remain unchanged according to recipient recovery patterns, which may also inform patient prognosis.

Although the MELD score system is invaluable and widely used for patients with end-stage liver disease for its convenience and simplicity, other prognostic indicators for critically ill patients in an intensive care unit (ICU) may be useful, such as acute physiology and chronic health evaluation (APACHE) II and sequential organ failure assessment (SOFA) scoring systems, which are used for mortality prediction from cirrhosis in the ICU patients [14-16]. Comparing the predictive ability of MELD scores and these ICU severity scores may be useful.

We therefore investigated whether changes in MELD scores or other ICU severity scores in the early post-transplant period were associated with mortality in LT recipients.

\section{Materials and Methods}

We collected perioperative and survival data in LT patients from November, 2003, to August, 2008, after approval of the Institutional Review Board at our university. Only adult $(\geq 18$ years) living donor LT cases were included. Transplantation was performed between the right hepatic lobes of both recipient and donor. Perioperative patient management was guided by routine LT protocols at our hospital. The electrical medical recoding system and chart system of the Transplantation Center at our hospital were used for this collection. The end point of this study was 1-year mortality after transplantation, and we studied the following variables.

Recipient pre-transplant variables: age, Child-Pugh-Turcott (CPT) class C, MELD score, emergency surgery, heart disease history, hepatorenal syndrome, hepatic encephalopathy, ascites ( $\geq 1 \mathrm{~L}$ ), alanine aminotransferease (ALT) level, and hyponatremia $\left(\mathrm{Na}^{+}<130 \mathrm{mmol} / \mathrm{L}\right)$.

Recipient intraoperative variables: last lactate concentration, packed red cell transfusion, reperfusion syndrome, and surgery time.

Donor variables: age, graft macrosteatosis $\geq 20 \%$, graft recipient weight ratio (GRWR).

Recipient post-transplant variables (within 7 days after surgery): reoperation, infection, pulmonary complication, low urine output ( $<1 \mathrm{ml} / \mathrm{kg} / \mathrm{h})$, prolonged mechanical ventilation $(\geq 24$ hours), APACHE II score, SOFA score on the $1^{\text {st }}$ post-transplant day.

Post-MELD scores were calculated on the 1st, 3rd, 5th, 7th, 14th, and 30th post-transplant day, using the formula: $\mathrm{R}=9.6$ $\times \log _{\mathrm{e}}($ creatinine $\mathrm{mg} / \mathrm{dl})+3.8 \times \log _{\mathrm{e}}$ (bilirubin $\left.\mathrm{mg} / \mathrm{dl}\right)+11.20$ $\times \log _{\mathrm{e}}$ INR +6.4 , as reported by Kamath et al. [17]. Declines in post-MELD scores from the $1^{\text {st }}$ day post-MELD score until the $3^{\text {rd }}\left(D_{3}\right), 5^{\text {th }}\left(D_{5}\right), 7^{\text {th }}\left(D_{7}\right), 14^{\text {th }}\left(D_{14}\right), 30^{\text {th }}$ post-transplant day $\left(D_{30}\right)$ were also calculated.

\section{Statistical methods}

Predictive factors for mortality after LT were analyzed by Cox's proportional hazards regression model. Relative risks were calculated as proportional hazard ratio (HR) for each probable perioperative variable in a univariate model. Before multivariate analyses, selected continuous variables $(\mathrm{P}<0.05)$ were dichotomized at their median, at clinically meaningful cutoff points, or at the point with maximal sensitivity and specificity for mortality by the analysis of area under the Receiver Operating Characteristic (ROC) curve. We performed multivariate analyses using a forward and backward stepwise Cox's regression model with the likelihood ratio test statistic. Results by multivariate analyses were displayed as HR, 95\% 
confidence interval (CI), and P-value. Two side P values less than 0.05 were considered statistically significant. SPSS version 15.0 for Windows (SPSS Inc, Chicago, IL, USA) was used for most statistical analyses and ROC curve analysis was conducted using MEDCALC for Windows version 11.0 (MedCalc Software, Mariakerke, Belgium).

\section{Results}

Of 281 patients who underwent LT during the study period, 269 patients were included, with exclusions of 9 cadaver donations and 3 pediatric cases. Baseline demographics of LT recipients and donors are shown in Table 1. More recipients (11\%) were older than 60 years than donors (1.5\%). Recipients were predominantly male, and $56.1 \%$ had liver cirrhosis resulting from hepatitis $B$ virus infection. Mean MELD scores of the recipients was 18.8 points at the pre-transplant period, and increased to 20.6 points just after transplantation. MELD scores then declined by more than 7 points until the 5 th posttransplant day.

The 1-year mortality rate of LT recipients was $17.1 \%(n=41)$. Eighteen (43.9\%) deaths were associated with graft failure,
Table 1. Baseline Demographics of Recipients and Donors with Liver Transplantation

\begin{tabular}{lc}
\hline Recipients $(\mathrm{n}=269)$ & $49.0 \pm 9.1$ \\
Age $(\mathrm{yr})$ & $71.4 / 28.6$ \\
Gender, M/F $(\%)$ & $23.9 \pm 3.0$ \\
Body mass index $\left(\mathrm{kg} / \mathrm{m}^{2}\right)$ & \\
Diagnosis & $151(56.1)$ \\
Hepatitis B cirrhosis & $97(36.1)$ \\
Hepatocellular carcinoma with cirrhosis & $29(10.8)$ \\
Acute fulminant hepatic failure & $21(7.8)$ \\
Alcoholic cirrhosis & $18.8 \pm 8.5$ \\
Pre-transplant MELD score (pts) & \\
Post-transplant MELD score $(\mathrm{pts})$ & $20.6 \pm 6.1$ \\
On the 1st day & $15.0 \pm 6.8$ \\
On the 3rd day & $13.2 \pm 5.4$ \\
On the 5th day & $11.9 \pm 5.6$ \\
On the 7th day & $10.4 \pm 6.0$ \\
On the 14th day & $9.9 \pm 5.9$ \\
On the 30th day & $24(8.9)$ \\
Hypertension & $56(20.8)$ \\
Diabetes & \\
Donors (n = 269) & $33.5 \pm 11.2$ \\
Age (yr) & $64.9 / 35.1$ \\
Gender, M/F $(\%)$ & $23.3 \pm 2.8$ \\
Body mass index $\left(\mathrm{kg} / \mathrm{m}^{2}\right)$ &
\end{tabular}

Data are presented as mean \pm SD or number (\%), MELD: model for end stage liver disease.

Table 2. Hazard Ratios for Mortality after Liver Transplantation According to Perioperative Variables

\begin{tabular}{|c|c|c|c|c|}
\hline Variables & $\beta$ & HR & $95 \% \mathrm{CI}$ & $P$ value \\
\hline \multicolumn{5}{|l|}{ Pre-transplant } \\
\hline Age (yr) & 0.01 & 1.01 & $0.98-1.01$ & 0.550 \\
\hline Child-Pugh-Turcott class C (Y/N) & -0.43 & 0.65 & $0.35-1.21$ & 0.176 \\
\hline Emergency surgery $(\mathrm{Y} / \mathrm{N})$ & 0.61 & 1.84 & $0.72-4.69$ & 0.201 \\
\hline Heart disease $(\mathrm{Y} / \mathrm{N})$ & -0.08 & 0.93 & $0.33-2.60$ & 0.887 \\
\hline Ascites $\geq 1 \mathrm{~L}(\mathrm{Y} / \mathrm{N})$ & -0.36 & 0.70 & $0.35-1.39$ & 0.307 \\
\hline Hepatorenal syndrome $(\mathrm{Y} / \mathrm{N})$ & 0.16 & 1.17 & $0.46-2.99$ & 0.736 \\
\hline Hepatic encephalopathy $(\mathrm{Y} / \mathrm{N})$ & -0.38 & 0.68 & $0.44-1.06$ & 0.086 \\
\hline Alanine aminotransferease (U/L) & 0.01 & 1.00 & $0.99-1.02$ & 0.601 \\
\hline Hyponatremia $(\mathrm{Y} / \mathrm{N})$ & 0.20 & 1.22 & $0.30-5.07$ & 0.781 \\
\hline \multicolumn{5}{|l|}{ Intraoperative } \\
\hline Last lactate concentration $(\mathrm{mmol} / \mathrm{L})$ & 0.07 & 1.07 & $1.00-1.16$ & 0.058 \\
\hline Packed red cell transfusion (units) & 0.02 & 1.02 & $0.98-1.05$ & 0.820 \\
\hline Reperfusion syndrome (Y/N) & 0.09 & 1.09 & $0.15-7.96$ & 0.929 \\
\hline Surgery time (min) & 0.09 & 1.09 & $0.90-1.32$ & 0.381 \\
\hline \multicolumn{5}{|l|}{ Donor } \\
\hline Age (years) & -0.01 & 0.99 & $0.97-1.03$ & 0.941 \\
\hline Graft macrosteatosis $\geq 20 \%$ (Y/N) & -0.64 & 0.53 & $0.13-2.19$ & 0.379 \\
\hline Graft recipient weight ratio (\%) & -0.11 & 0.89 & $0.17-4.66$ & 0.893 \\
\hline \multicolumn{5}{|l|}{ Post-transplant } \\
\hline Reoperation (Y/N) & 1.12 & 3.06 & $1.46-6.42$ & 0.003 \\
\hline Infection $(\mathrm{Y} / \mathrm{N})$ & -0.31 & 0.74 & $0.39-1.38$ & 0.340 \\
\hline Pulmonary complication (Y/N) & 0.95 & 2.58 & $1.32-5.06$ & 0.006 \\
\hline Low urine output $(<1 \mathrm{ml} / \mathrm{kg} / \mathrm{hr})(\mathrm{Y} / \mathrm{N})$ & 0.60 & 1.83 & $0.91-3.66$ & 0.089 \\
\hline Prolonged mechanical ventilation $=24$ hours $(\mathrm{Y} / \mathrm{N})$ & 1.74 & 5.72 & $2.92-11.21$ & $<0.001$ \\
\hline APACHE II score (pts)* & -0.12 & 0.89 & $0.78-1.01$ & 0.068 \\
\hline SOFA score (pts) ${ }^{\dagger}$ & -0.22 & 0.80 & $0.65-1.00$ & 0.047 \\
\hline
\end{tabular}

CI: confidence interval, HR: hazard ratio. *Acute physiology and chronic health evaluation score on the 1st post-transplant day, ${ }^{\dagger}$ Sequential organ failure assessment score on the 1st post-transplant day. 
and infectious complications such as pneumonia or sepsis were the second most common cause of death $(n=14,34.1 \%)$. Cancer recurrence or metastasis $(14.6 \%)$, cardiac problems (9.8\%), bleeding ( $7.3 \%)$, suicide $(4.9 \%)$, and renal failure $(2.5 \%)$ followed as causes of death. The incidence of death cases with more than one cause of death was $26.8 \%$, including multiorgan failure $(7.3 \%)$. In univariate analysis, no pre-transplant, intraoperative, or donor variables were associated with mortality. Only post-transplant variables such as reoperation, pulmonary complication, prolonged mechanical ventilation $\geq 24$ hours until the 7 th post-transplant day, and SOFA score on the 1st post-transplant day were related to 1-year mortality after LT $(\mathrm{P}<0.05$, Table 2).

The association of MELD score related variables with mortality is displayed in Table 3. Pre-MELD and post-MELD scores on the 1st and 3rd day had no influence on 1-year mortality. After the 5 th post-transplant day, all post-MELD scores had meaningful associations with 1-year mortality $(\mathrm{P}<$ 0.05). Changes in MELD score did not show a relationship with mortality. Only $\mathrm{D}_{5}$ and $\mathrm{D}_{30}$ were significant $(\mathrm{P}<0.05)$, and could enter the next multivariate analyses. The cutoff point of $D_{5}$ with the maximal combination of sensitivity and specificity for mortality by ROC curve analysis was 5 points.

Through multivariate analysis, we could establish a predictive model of mortality that included post-transplant prolonged mechanical ventilation $\geq 24$ hours and decline in post-MELD score (Table 4). No post-MELD scores were significant in the final multivariate analysis. Instead, $\mathrm{D}_{5}$ less than 5 points was identified as the earliest independent predictor of 1-year mortality in living donor LT (HR 2.35, 95\% CI 1.27-4.68, P = 0.007).

Post-MELD declines reflect 1-year mortality, as shown in the survival graph (Fig. 1). Patients with $\mathrm{D}_{5}$ less than 5 points showed significantly lower 1-year mortality than patients with $\mathrm{D}_{5}$ higher than 5 points $(74.1 \%$ vs $88.4 \%, \mathrm{P}=0.004)$.

\section{Discussion}

The MELD score was adopted for the organ allocation system in the United States in 2002, and was originally designed to assess the short-term mortality of patients with portal hypertension undergoing transjugular intrahepatic portosystemic shunt [6]. However, its simplicity to calculate and inclusion of important items have increased its use for predicting intraoperative or post-transplant outcomes as well as pre-transplant complications in patients who underwent LT. In addition to predicting the three month mortality of patients on LT waiting lists [18], a MELD score higher than 30 points

Table 3. Hazard Ratios for Mortality after Liver Transplantation According to Model for End-stage Liver Disease (MELD) Scores

\begin{tabular}{|c|c|c|c|c|c|}
\hline Variables & $\beta$ & HR & $95 \% \mathrm{CI}$ & $\mathrm{P}$ value & Cutoff point* \\
\hline Pre-transplant MELD score (pts) & 0.01 & 1.01 & $0.97-1.04$ & 0.785 & \\
\hline \multicolumn{6}{|l|}{ Post-transplant MELD score (pts) } \\
\hline On the $1^{\text {st }}$ day & -0.02 & 0.99 & $0.94-1.04$ & 0.568 & \\
\hline On the $3^{\text {rd }}$ day & -0.02 & 0.98 & $0.93-1.03$ & 0.427 & \\
\hline On the $5^{\text {th }}$ day & 0.06 & 1.07 & $1.01-1.13$ & 0.017 & 13 \\
\hline On the $7^{\text {th }}$ day & 0.05 & 1.05 & $1.00-1.09$ & 0.034 & 11 \\
\hline On the $14^{\text {th }}$ day & 0.05 & 1.05 & $1.01-1.09$ & 0.008 & 8 \\
\hline On the $30^{\text {th }}$ day & 0.15 & 1.16 & $1.12-1.20$ & $<0.001$ & 11 \\
\hline \multicolumn{6}{|c|}{ Decline in post-transplant MELD score (pts) ${ }^{\dagger}$} \\
\hline Until the $3^{\text {rd }}$ day $\left(D_{3}\right)$ & -0.02 & 0.99 & $0.94-1.04$ & 0.568 & \\
\hline Until the $5^{\text {th }}$ day $\left(D_{5}\right)$ & -0.04 & 0.96 & $0.93-0.99$ & 0.044 & 5 \\
\hline Until the $7^{\text {th }}$ day $\left(D_{7}\right)$ & -0.03 & 0.97 & $0.93-1.00$ & 0.062 & \\
\hline Until the $14^{\text {th }}$ day $\left(\mathrm{D}_{14}\right)$ & -0.03 & 0.97 & $0.94-1.00$ & 0.074 & \\
\hline Until the $30^{\text {th }}$ day $\left(D_{30}\right)$ & -0.10 & 0.91 & $0.88-0.94$ & $<0.001$ & 1 \\
\hline
\end{tabular}

CI: confidence interval, HR: hazard ratio, *By the analysis of the area under receiver operating characteristic (ROC) curve, ${ }^{\dagger}$ Difference from the MELD score on the 1st post-transplant day.

Table 4. Predictive Model for Mortality after Living Donor Liver Transplantation by Multivariate Cox's Proportional Hazards Regression Model

\begin{tabular}{lccc}
\hline & $\beta$ & HR & P value \\
\hline $\begin{array}{l}\text { Post-transplant prolonged mechanical } \\
\text { ventilation } \geq 24 \text { hours }\end{array}$ & 1.69 & 5.43 & $2.77-10.67$ \\
$\mathrm{D}_{5}^{*}$ less than 5 points & 0.89 & 2.35 & 0.001 \\
\end{tabular}

*Decline in post-transplant model for end-stage liver disease score from the 1st day until the 5th post-transplant day. 


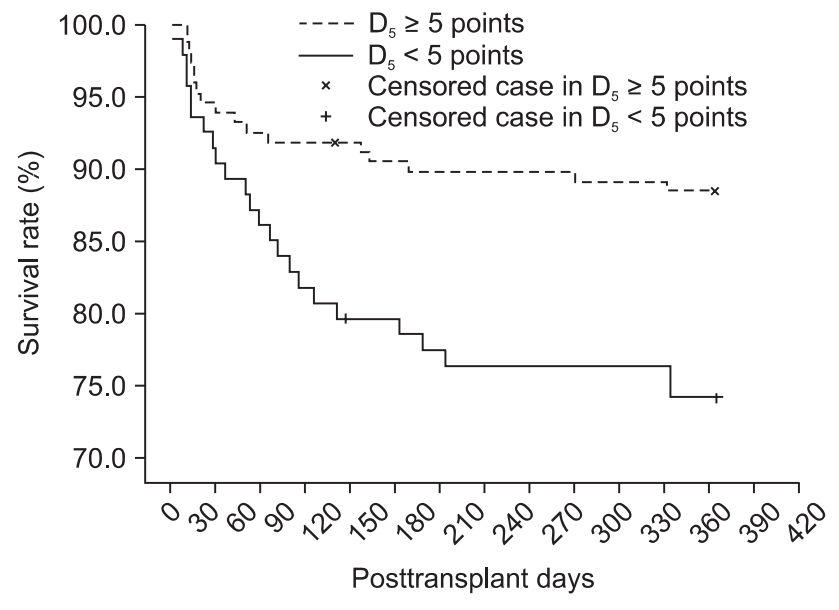

Fig. 1. Comparison of survival rates between patients with and without $\mathrm{D}_{5}$ less than 5 points. The patients with $\mathrm{D}_{5}$ less than 5 points show a significantly lower 1-year survival rate than those without $\mathrm{D}_{5}$ less than 5 points $(74.1 \%$ vs $88.4 \%$; $\mathrm{P}=0.004$, by log-rank test in Kaplan-Meier analysis). $\mathrm{D}_{5}$ : decline in post-transplant MELD score from the 1st day until the 5 th post-transplant day.

indicates higher requirements for intraoperative transfusion and vasopressors $[19,20]$. However, pre-MELD score is not sufficiently reliable as a predictor of mortality $[21,22]$. This study also indicated pre-MELD score did not predict post-transplant mortality.

LT Patients have different pre-transplant and post-transplant situations. In particular, transplanted liver graft and immune suppression are critical for patient management and prognosis [23], with infection, recurrence of primary liver disease, and side effects of immunosuppressants playing critical roles in mortality $[2,3,24]$. Pre-transplant factors may help predict posttransplant mortality $[4,25]$, but the survival of LT recipients depends on immunological or functional recovery of the liver graft.

Causes of mortality after LT are categorized as either graftrelated or non-graft related. The main cause for graft-related mortality is recurrence of primary disease or hepatitis virus, and for non-graft related mortality is a cardiovascular event or de novo malignancy [2]. The riskiest time period for mortality is the first post-transplant year, particularly the first three months [26,27], with primary causes of mortality that include graft dysfunction, technical problems, and infection [28]. Graftrelated deaths cause more than half of all mortality. Graft failure in cadaveric donor LT is influenced by donor age, donation after cardiac death, and split/partial grafts [29]. Living donor LT may have other risk predictors for graft failure, including small size discrepancy for metabolic requirements, or vascular problems resulting from thrombosis, or mechanical twisting because of smaller sizes. Liver graft evaluation and prediction system for early post-transplant may therefore be more useful than pre- transplant ones.

The MELD score is a good indicator of liver graft status because it measures bilirubin, INR, and renal function, and is simple to calculate. Pre-transplant renal dysfunction with estimated glomerular filtration rates $<30 \mathrm{ml} / \mathrm{min} / 1.73 \mathrm{~m}^{2}$ is often restored after LT, but immunosuppression frequently induces chronic kidney diseases [10]. Post-transplant kidney disease is a common complication after LT and impacts graft and patient survival $[11,30]$. A pre-MELD score $\geq 20$ points had a higher incidence of post-LT chronic renal failure and higher mortality rate [31]. We therefore assessed post-MELD scores for comparison with other mortality indicators [32], and it was reliable in predicting short-term mortality at less than 90 days $[12,13]$.

We showed that the post-MELD score could predict longterm mortality (1 year), but the pre-MELD score did not. Graftrelated problems were the leading cause of death, so postMELD score may reflect these graft-related problems. Renal failure did not contribute to death as much as we expected, and perioperative variables were not associated with mortality.

APACHE II scores, SOFA score, simplified acute physiology score (SAPS), and multiple organ dysfunction score (MODS) are ICU severity scoring systems used in mortality prediction $[33,34]$. In cirrhotic patients, SOFA score has been compared to other ICU severity scores, including APACHE II, failing organ systems (FOS), organ system failure (OSF), and liver specific scores including Child-Pugh-Turcott classification and MELD score $[15,16]$. SOFA was the most accurate predictor of mortality through analysis of the area under the ROC curves, but requires follow-up measurement. The score at $48 \mathrm{~h}$ after ICU admission or mean scores of multiple measurements are better than baseline scores on ICU admission day. APACHE II can also predict mortality in LT patients [14], although it tends to overestimate mortality rate in LT patients. We used 1-day posttransplant SOFA or APACHE II scores to capture the earliest indicator of mortality [35]. However, SOFA score showed a negative correlation with the mortality, potentially because the poor clinical condition on day 1 makes those scores less useful for determining mortality. Follow-up ICU scores after the $1^{\text {st }}$ post-transplant day may improve the predictive power of these tests and should include more patients.

The prognostic model of mortality in this study included prolonged mechanical ventilation during the ICU period after LT, which is a known risk factor for mortality after LT [36]. Intraoperative variables such as blood loss, urine volume, and postoperative renal failure may contribute to prolonged mechanical ventilation [37]. We developed a post-MELD for testing mortality at 1 year, and that included bilirubin and creatinine to measure early renal or allograft failure [32]. The MELD scores after the $5^{\text {th }}$ post-transplant day showed the best 
mortality prediction, which was much earlier than $14^{\text {th }}$ day postMELD scores used previously [13]. Furthermore, we measured changes in MELD score over time. A sluggish decline in MELD score indicates slow recovery or a failing graft. After adjustment for other confounding factors, the sequential observation of MELD scores had better prognostic ability than static assessment on a designated post-transplant day. In particular, a decline $<5$ points (from the $1^{\text {st }}$ day post-MELD score) until the $5^{\text {th }}$ post-transplant day is the earliest predictor of mortality after LT.

This study has some inherent limitations as a retrospective study. Incomplete data was substituted with medians, but the patient population was small. A differentiated approach according to LT diagnosis (e.g. cirrhosis versus cancer) or cause of death might improve clinical application of the results. However, the use of 1-year mortality rates and changing postMELD scores over time are important contribution of the study.

In conclusion, the post-MELD score could reflect 1 -year mortality after LT, whereas pre-MELD, APACHE II, and SOFA scores did not. In particular, a sluggish decline in the postMELD score of less than 5 points until the 5 th day (from the 1st day post-MELD score) is the earliest independent predictor of 1-year mortality after LT.

\section{Acknowledgements}

We sincerely appreciate the support from the Clinical Research Coordinating Center (CRCC) at the College of Medicine, Catholic University of Korea for statistic analyses and the Transplantation Center at Seoul St. Mary's hospital for data collection on donor and recipient survival.

\section{References}

1. Burroughs AK, Sabin CA, Rolles K, Delvart V, Karam V, Buckels J, et al. 3-month and 12-month mortality after first liver transplant in adults in Europe: predictive models for outcome. Lancet 2006; 367: 225-32.

2. Vogt DP, Henderson JM, Carey WD, Barnes D. The long-term survival and causes of death in patients who survive at least 1 year after liver transplantation. Surgery 2002; 132: 775-80.

3. Hellinger WC, Crook JE, Heckman MG, Diehl NN, Shalev JA, Zubair AC, et al. Surgical site infection after liver transplantation: risk factors and association with graft loss or death. Transplantation 2009; 87: 1387-93.

4. Sanchez-Perez B, Santoyo J, Fernandez-Aguilar JL, Suarez MA, Perez JA, Jimenez M, et al. Preoperative factors and models predicting mortality in liver transplantation. Transplant Proc 2005; 37: 1499-501.

5. Boin IF, Leonardi MI, Luzo AC, Cardoso AR, Caruy CA, Leonardi LS. Intraoperative massive transfusion decreases survival after liver transplantation. Transplant Proc 2008; 40: 789-91.
6. Malinchoc M, Kamath PS, Gordon FD, Peine CJ, Rank J, ter Borg PC. A model to predict poor survival in patients undergoing transjugular intrahepatic portosystemic shunts. Hepatology 2000; 31: 864-71.

7. Xia VW, Taniguchi M, Steadman RH. The changing face of patients presenting for liver transplantation. Curr Opin Organ Transplant 2008; 13: 280-4.

8. Desai NM, Mange KC, Crawford MD, Abt PL, Frank AM, Markmann JW, et al. Predicting outcome after liver transplantation: utility of the model for end-stage liver disease and a newly derived discrimination function. Transplantation 2004; 77: 99-106.

9. Saab S, Wang V, Ibrahim AB, Durazo F, Han S, Farmer DG, et al. MELD score predicts 1-year patient survival post-orthotopic liver transplantation. Liver Transpl 2003; 9: 473-6.

10. Lee JP, Heo NJ, Joo KW, Yi NJ, Suh KS, Moon KC, et al. Risk factors for consequent kidney impairment and differential impact of liver transplantation on renal function. Nephrol Dial Transplant 2010; 25: 2772-85.

11. Bahirwani R, Reddy KR. Outcomes after liver transplantation: chronic kidney disease. Liver Transpl 2009; 15 Suppl 2: S70-4.

12. Briceno J, Sanchez-Hidalgo JM, Naranjo A, Ciria R, Pozo JC, Luque A, et al. Model for end-stage liver disease can predict very early outcome after liver transplantation. Transplant Proc 2008; 40: 29524.

13. Kim JD, Choi JY, Kwon JH, Jang JW, Bae SH, Yoon SK, et al. Performance of posttransplant model for end-stage liver disease (MELD) and delta-MELD scores on short-term outcome after living donor liver transplantation. Transplant Proc 2009; 41: 3766-8.

14. Angus DC, Clermont G, Kramer DJ, Linde-Zwirble WT, Pinsky MR. Short-term and long-term outcome prediction with the Acute Physiology and Chronic Health Evaluation II system after orthotopic liver transplantation. Crit Care Med 2000; 28: 150-6.

15. Cholongitas E, Betrosian A, Senzolo M, Shaw S, Patch D, Manousou $\mathrm{P}$, et al. Prognostic models in cirrhotics admitted to intensive care units better predict outcome when assessed at $48 \mathrm{~h}$ after admission. J Gastroenterol Hepatol 2008; 23(8 Pt 1): 1223-7.

16. Cholongitas E, Senzolo M, Patch D, Shaw S, Hui C, Burroughs AK. Review article: scoring systems for assessing prognosis in critically ill adult cirrhotics. Aliment Pharmacol Ther 2006; 24: 453-64.

17. Kamath PS, Wiesner RH, Malinchoc M, Kremers W, Therneau TM, Kosberg CL, et al. A model to predict survival in patients with endstage liver disease. Hepatology 2001; 33: 464-70.

18. Wiesner R, Edwards E, Freeman R, Harper A, Kim R, Kamath P, et al. Model for end-stage liver disease (MELD) and allocation of donor livers. Gastroenterology 2003; 124: 91-6.

19. Xia VW, Fond A, Du B. Ascites, but not hyponatremia, is associated with high intraoperative transfusion and vasopressor requirements during liver transplantation. Transplant Proc 2006; 38: 1398-9.

20. Xia VW, Du B, Braunfeld M, Neelakanta G, Hu KQ, Nourmand H, et al. Preoperative characteristics and intraoperative transfusion and vasopressor requirements in patients with low vs. high MELD scores. Liver Transpl 2006; 12: 614-20.

21. Yoo HY, Thuluvath PJ. Short-term postliver transplant survival after the introduction of MELD scores for organ allocation in the United States. Liver Int 2005; 25: 536-41.

22. Hayashi PH, Forman L, Steinberg T, Bak T, Wachs M, Kugelmas 
M, et al. Model for End-Stage Liver Disease score does not predict patient or graft survival in living donor liver transplant recipients. Liver Transpl 2003; 9: 737-40.

23. Desai M, Neuberger J. Chronic liver allograft dysfunction. Transplant Proc 2009; 41: 773-6.

24. Beckebaum S, Sotiropoulos GC, Klein CG, Broelsch CE, Saner F, Paul A, et al. Predictive factors of outcome in patients transplanted for hepatitis B. Transplantation 2009; 87: 872-81.

25. Weismuller TJ, Prokein J, Becker T, Barg-Hock H, Klempnauer J, Manns MP, et al. Prediction of survival after liver transplantation by pre-transplant parameters. Scand J Gastroenterol 2008; 43: 736-46.

26. Mora NP, Klintmalm GB, Solomon H, Goldstein RM, Gonwa TA, Husberg BS. Survival after liver transplantation in 300 consecutive patients: the influence of age, clinical status, and pretransplant disease. Transplant Proc 1992; 24: 156-7.

27. Shaw BW Jr, Wood RP, Stratta RJ, Pillen TJ, Langnas AN. Stratifying the causes of death in liver transplant recipients. An approach to improving survival. Arch Surg 1989; 124: 895-900.

28. Cuervas-Mons V, Julio Martinez A, Dekker A, Starzl TE, Van Thiel DH. Adult liver transplantation: an analysis of the early causes of death in 40 consecutive cases. Hepatology 1986; 6: 495-501.

29. Feng S, Goodrich NP, Bragg-Gresham JL, Dykstra DM, Punch JD, DebRoy MA, et al. Characteristics associated with liver graft failure: the concept of a donor risk index. Am J Transplant 2006; 6: 783-90.

30. Narayanan Menon KV, Nyberg SL, Harmsen WS, DeSouza NF,
Rosen CB, Krom RA, et al. MELD and other factors associated with survival after liver transplantation. Am J Transplant 2004; 4: 819-25.

31. Sharma P, Welch K, Eikstadt R, Marrero JA, Fontana RJ, Lok AS. Renal outcomes after liver transplantation in the model for endstage liver disease era. Liver Transpl 2009; 15: 1142-8.

32. Xu X, Ling Q, Wu J, Chen J, Gao F, Feng XN, et al. A novel prognostic model based on serum levels of total bilirubin and creatinine early after liver transplantation. Liver Int 2007; 27: 816-24.

33. Khwannimit B. A comparison of three organ dysfunction scores: MODS, SOFA and LOD for predicting ICU mortality in critically ill patients. J Med Assoc Thai 2007; 90: 1074-81.

34. Khwannimit B, Bhurayanontachai R. The performance of customised APACHE II and SAPS II in predicting mortality of mixed critically ill patients in a Thai medical intensive care unit. Anaesth Intensive Care 2009; 37: 784-90.

35. Wong CS, Lee WC, Jenq CC, Tian YC, Chang MY, Lin CY, et al. Scoring short-term mortality after liver transplantation. Liver Transpl 2010; 16: 138-46.

36. Medeiros DM, Oliveira AC, Barros MF, Cury RA, Sette H Jr, Abdala E, et al. Early mortality in liver transplantation: bilirubin as predictor of outcome. Transplant Proc 2004; 36: 931-2.

37. Li Q, Yao G, Ge Q, Yi M, Gao J, Zhu X. Relevant risk factors affecting time of ventilation during early postoperative period after orthotopic liver transplantation. J Crit Care 2010; 25: 221-4. 